\title{
PROMOTING SELF-REGULATORY SKILLS IN SELF-REGULATED LEARNING PRE-SCHOOL EDUCATION STAGE 3
}

\author{
Ilze Šūmane, Līga Āboltiṇa \\ University of Latvia, Latvia
}

\begin{abstract}
The competence approach in pre-school education, which recommends the promotion of self-regulated learning, raises questions about its impact on the development of children's self-regulation. As a cross-cutting skill, self-regulated learning is essential for today's society. It provides for a person's ability to self-educate and develop effectively and successfully. The environment of the pre-school institution and the teacher, who equips and improves this environment, play an important role in promoting the child's self-regulated learning. In the third stage of pre-school education children have reached the age of 5 to 6 years old and are being prepared to start school. The aim of this study is to assess and analyse children's self-regulation skills in a pre-primary education environment in the third stage of self-regulated learning. Self-regulated learning is when a student is able to function and use cognitive, emotional processes and behavioural regulation tools to achieve learning goals. The following research tasks were included: 1) analyse the essence and development of selfregulation, and guidelines for organising a self-regulated learning process; and 2) carry out pedagogical observations of children's self-regulatory abilities within the framework of the self-regulated learning process.

The research methods included analysis of pedagogical and psychological literature and sources, pedagogical observation, and statistical analysis of data. The study involved 41 children who were 5 to 6 years old. The results of the study show that self-directed learning can significantly promote the development of self-regulation skills in 5 to 6 -year-old children. To better develop the process of self-regulation for 5 to 6-year-old children, the selfregulated learning process must be easier to understand, with an emphasis on updating, understanding, and reflecting on the learned content, while also clearly articulating the expected outcomes and providing feedback.
\end{abstract}

Keywords: pre-school education, pre-school environment, self-regulation, self-regulatory skills, self-regulated learning, 5 to 6-year-old children. 


\section{Introduction}

In 2019, starting with pre-school, there was a gradual change of approach throughout the general education system in Latvia. This entailed the development of competence-based learning content and approaches. In pre-school, this included creating a learning environment that encourages children to self-regulate their exploration of the world and developing children's self-regulated learning skills. Two years after the change of approach, it is important to study how the related goals are being achieved. Self-regulated learning is one of the six cross-cutting skill groups included in the advanced curriculum (Cabinet regulations, 2018 (716)). In the third stage of pre-school education, children have reached the age of 5 to 6 years old and are preparing to start school, so it is important to evaluate these children's self-regulation and self-regulated learning skills. Research shows that a successful transition from pre-school to school requires high self-regulatory skills (Blair, 2002).

The aim of this study is to assess and analyse children's self-regulation skills in a pre-primary education environment education in the third stage of self-regulated learning.

The following research tasks were included: 1) analyse the essence and development of self-regulation, and guidelines for organising a self-regulated learning process; and 2) carry out pedagogical observation of children's self-regulatory abilities within the framework of the self-regulated learning process.

The research methods included analysis of pedagogical and psychological literature and sources, pedagogical observation, and statistical analysis of data.

In recent decades, the concept of psychology has become increasingly important in the educational sciences. Psychological skills are now recognized as being important in the learning process and in achieving various goals, as they are associated with willpower, self-control, emotion regulation and self-management (Braaka et al., 2019; Murray et al., 2015; Posner \& Rothbart, 2000; Rothbart \& Bates, 2006; Zimmerman, 2005; Zimmerman \& Schunk, 2011).

Self-regulation is defined as the process of managing thoughts and feelings so that a person can perform purposeful activities, such as organising behaviour, controlling impulses, and constructively solving problems. It is related to the ability to focus and change focus and could work towards goals (Rosanbalm \& Murray, 2017). In the context of self-regulated learning, self-regulation is perceived as an active, constructive process in which students set their learning goals and then regulate and control their cognitive activity, motivation and behaviour (Pintrich, 2000). 
Self-regulation involves three overlapping areas: the cognitive domain, the emotional domain, and behaviour. It should be borne in mind that the cognitive and emotional domains together are a key element of regulated behaviour or action. Although these areas are distinguished in theory, it is generally accepted that they are interconnected in complex ways and it is difficult to separate these areas when measuring children's self-regulation (Murray et al., 2015).

Cognitive self-regulation includes focused attention, action, goal setting, self-control, evaluation, problem solving and decision making, as well as the ability to think about action, make plans, and ignore (Braaka et al., 2019; Savina, 2021; Liman \& Tepeli, 2019; Zimmerman \& Schunk, 2011).

Emotional self-regulation involves the active management of strong and unpleasant feelings. It requires attention to and understanding of emotions, and includes the management of self-reassuring strategies, tolerance, and inner suffering. Emotional self-regulation also involves empathy and compassion for other people (Calkins, 2004; Murray et al., 2015).

The self-regulation of behaviour includes adaptation, perseverance, impulse control, conflict resolution, the use of active reconciliation and coping strategies, goal-oriented behaviour, and stopping inappropriate behaviour. A lack of self-regulation can lead to impulsivity, aggressive behaviour, difficulty concentrating, and involvement in risky activities (Liman \& Tepeli, 2019; Murray et al., 2015).

Educational institutions set many requirements for students' self-regulation to adjust their behaviour in accordance with class regulations. Appropriate behaviour influences students' relationships with teachers and collaborative relationships promote learning. Studies show that the process of self-regulation correlates with early education skills and children with better self-regulation abilities are better prepared for learning (Braaka et al., 2019). Effective classroom management, creating environments with clear structures, and involving children in the planning and evaluation of activities increases students' self-regulation as well as their academic achievements (Braaka et al., 2019; Lonigan et al., 2017; Savina, 2021).

At the age of 5 or 6 , children experience rapid growth that is directly related to self-regulation (Lonigan et al., 2017). Their intentional attention increases, they begin to use rules, strategies and planning to guide appropriate behaviour and language begins to control their emotional reactions and actions. When a child is excited, he or she begins to model the action, use self-calming strategies, and use words to express emotions (Murray et al., 2015). This age group is very suitable for adults to provide teaching and training on the skills needed to recognise emotions, problem solving, perspective acceptance, and calming strategies. These skills need to be repeated, encouraged, and practiced by children. It is also 
important for adults who come into contact with children to apply these skills themselves, as children watch adults closely to learn how to behave (Rosanbalm \& Murray, 2017).

The development of self-regulation is facilitated by the interaction of the child's personality with other people and the environment. Researchers point out that creating an environment in which children have many opportunities to practice self-regulatory skills is a very important condition for development (Blair, 2003; Braaka et al., 2019; McClelland \& Cameron, 2012; Murray et al., 2015). The development of self-regulatory abilities in children requires a structured environment, supportive relationships, and direct instructions and training on the development of self-regulatory skills. It is recommended to use five to six institutional rules for completing tasks, relationships with others, and moving around the room as an external stimulus to guide students' behaviour. Daily routine also helps to predict future activities and tasks. Further, a structured environment entails a physically and emotionally safe environment with a consistent, predictable order according to the students' level of development (Rosanbalm \& Murray, 2017). These are essential conditions for creating a pre-school environment to promote the development of children's self-regulatory skills.

The importance of self-regulated learning in early childhood has been emphasised by several studies (Becker et al., 2014; Braaka et al., 2019; Dörr \& Perels, 2019; Liman \& Tepeli, 2019). Theoretical concepts of self-regulated learning define it as a process in which individuals take initiative with or without the help of others, diagnose their learning needs, formulate learning objectives, identify the human and material resources needed for learning, select and implement appropriate learning strategies, and evaluate learning outcomes (Knowles, 1975; Pilling-Cormick \& Garrison, 2007). Selfregulated learning is a process in which the student is able to operate and use thinking, emotional processes and behaviour regulation tools to systematically guide themselves through their personal learning, and later in life, through their work and other personal goals (Zimmerman \& Schunk, 2011).

The general model of self-regulated learning is understood as a set of several cyclical activities, in each of which the student must try to act consciously through self-reflection. Most theoretical models of self-regulated learning distinguish three cyclical phases: planning, monitoring and evaluation (Boekaerts \& Corno, 2005; Panadero \& Järvelä, 2015; Pintrich, 2000; Zimmerman \& Schunk, 2011).

Based on the importance of the development of self-regulation during childhood, self-regulated learning has been included in the Latvian preschool curriculum. It is considered a pervasive skill necessary for general education, so that at the pre-school stage, "The child distinguishes emotions and identifies causes thereof, learns to control his or her behaviour, follows 
a daily routine, is able to wait, is able to complete an activity, dresses and organises his or her things independently, learns to set an objective of his or her activity, to plan an activity in order to realise his or her idea, acts independently, overcomes difficulties with support, learns to carry out the assigned task, is proud of his or her achievements, looks at the failures and mistakes as a part of learning, evaluates his or her activities, activities of others and results thereof, explains his or her evaluation" (Cabinet regulations 2018(716));

Research on pre-school learning should take children's developmental performance into account. A 5 to 6-year-old child is able to set goals, adjust their thinking, take action to achieve their goals, plan problem solving, sufficiently focus on skills, and talk about their learning process (Jacoba et al., 2019).

Based on the analysed research and the goals of the Latvian pre-school education system, a study on the self-regulatory skills of 5 to 6 -year-old children in the third stage of the self-regulated learning process was conducted.

\section{Method}

The aim of this research is to assess and analyse children's self-regulatory skills in pre-school education in the third stage of self-regulated learning. The main research question is: How do children's self-regulation skills develop during the self-directed learning process in the third stage of pre-school education?

In order to assess children's self-regulatory skills, it is necessary to develop a procedure for measuring the self-regulatory skills of 5 to 6 -yearold children.

Self-regulated learning is influenced by five groups of factors, namely, will and motivation, action, ability, behaviour, self-control and self-regulation, emotional characteristics, physiological characteristics, and intellectual activity (Murray et al., 2015; Pintrich, 2000; Zimmerman \& Schunk, 2011).

This study uses criteria for researching children's will and motivation, which, based on the analysis of theoretical approaches, should be considered the most important for promoting children's self-regulatory skills. In accordance with the criteria children were observed in the pedagogical process and the obtained data were analysed.

The factors of desire and motivation involve awareness of one's desires and the actions required to achieve one's goals, the ability to considered paramount for and overcome any obstacles without losing patience, and endurance during the action process. The criteria also include the ability to manage one's emotions by controlling one's behaviour, as well as the ability to independently manage and organise one's activities. 
Empirical research has been performed using pedagogical observation, collection and analysis of the obtained data.

The advantage of pedagogical observation is the identification of children's natural self-regulation skills during play activities organised and indirectly managed in the learning environment of the pre-school institution. In the pre-school environment, children work on four areas of study, which are languages, mathematics, science and technology. They are offered multi-level tasks, and activities take place both indoors and outdoors. There is a certain daily rhythm and activity plan, as well as group activities, subgroup tasks, and individual activities and games. Children work in groups, materials for children are freely available, and teachers regularly lead the students in reflecting on what has been accomplished.

This research was conducted in Latvia with two groups from pre-school educational institutions. The Microsoft Excel data processing program was used for processing and analysing the obtained data. The sample in this study consisted of 41 children aged 5 to 6 years old. All parents gave their written consent for the participation of their children in the study. Prior to the study there was an informative meeting held for pre-school teachers working with 5-6-year-old children. Teachers had been introduced to the self-regulation skills assessment criteria. The assessment of children's skills had been performed by pre-school teachers for one month in the daily pedagogical process; the results of the observation were recorded in the tables previously prepared by the researchers. The researchers then performed data collection and analysis.

Summarising the analysis in the theoretical framework, which characterises children's self-regulation skills, the study set out 25 criteria (see below) with the following corresponding indicators:

1) minimum intensity level

2) weak degree of intensity

3) medium intensity

4) pronounced intensity

5) maximum degree of intensity

In the study, the observation data were obtained using a standardised observation sheet, which included the following criteria: awareness of one's desires, awareness of why one wants to try to complete what has been started, ability to continue to work even if there is no desire, ability to persevere despite difficulties, ability to control one's emotions, ability to control one's behaviour, independent organisation of activities and actions, participation in the implementation of news and ideas, asking and answering questions about oneself and one's skills, cooperating with children, making decisions independently, choosing an activity independently, participating in group games, expressing his/her attitude towards what is 
happening, evaluating his/her own actions and those of others, arranging his/her workplace, being able to organise work, completing work that has been started, listening and perceiving what is heard (i. e., answers questions, explains, recounts, portrays mimicry), independently choosing materials for creative activity, expressing his/her attitude towards creative work, considering themselves as part of a family and a group, and enjoying learning.

\section{Results}

Data from a study averaging points on children's self-regulatory skills show that the criteria - continue to function even in the absence of desire or will, evaluate one's own actions and those of others, and control one's emotions (3 points). There was relatively low awareness of one's: wishes, ability to persevere in encountering difficulties, ability to control one's behaviour, ability to express one's attitude towards what is happening (3.2 points), independent organisation of actions, ability to ask and answer questions about oneself, skills, ability to organise work, ability to enjoy learning (3.3 points), ability to listen and perceive what is heard (i. e., answers questions, explains, tells), and ability to express his/her attitude towards creative work (3.4 points) -, which indicates moderate emotional and cognitive self-regulation among 5 to 6-year-old children. It can be concluded that children in the third stage of pre-school education need to promote self-control, assessment, expression of attitude, and organisation of their activities and learning activities.

Compared to the others, the highest indicator was awareness of belonging to a family and group (4.5 points), which confirms the importance of children having a sense of belonging to both peer and family groups during pre-school education. Children's self-regulation skills assessment of a relatively high-level results are the criteria - participates in group games (3.9 points), chooses activities independently (3.7 points) tends to advance what has been started to the end, participates in the implementation of news and ideas, independently makes decisions, arranges his/her workplace, completes the started work, independently chooses materials for creative activity (3.6 points), and cooperates with children (3.5 points) -, which in turn indicates the self-regulation of pronounced behaviour of 5 to 6-year-old children.

The study concluded that the majority of observed children (71\%) are aware of belonging to a group, engage in group games, independently choose an occupation, are responsible for the duties assigned to them, and know how to organise a workplace and independently choose materials for their work. 
When assessing each child individually, the intensity ratings differed greatly, because there were children who had high levels of intensity when it comes to the will and motivation factor (15\%). However, since there were children with markedly low intensity levels (18\%), the overall ratings were more in line with the average. The intensity level confirmed by the mean self-regulation index for children aged 5 to 6 years was 3.4 points in this study.

Based on the analysis of theoretical principles and the results of the research, in order to promote the self-regulation skills of 5 to 6-year-old children, it is recommended:

1) to plan multi-level tasks in play centres, taking into account different levels of children's abilities

2) to include, as a result, actions that promote children's will to overcome difficulties and become independent

3) that in the pedagogical process in pre-school, situations should be modelled in which the child can express his/her opinion and attitude, and learn to manage his/her emotions

4) to increase the child's self-control and self-assessment through feedback

5) to involve children in planning activities for joint activities

6) to offer a variety of tasks and flexible time to perform activities

7) to provide supportive feedback and an opportunity for the child to explain the course of activities as well as think about their learning and the achieved result

\section{Conclusions}

Self-regulation in the process of self-regulated learning is related to the development of the child's cognitive, emotional, and regulated behaviour. In the research, will and motivation can be distinguished from several groups of factors.

The pedagogical observations conducted as part of this study conclude that the following self-regulation skills for children in the third stage of pre-school education are not yet sufficiently developed: to continue to work even if there is no will or desire, to values one's own actions and those of others, the ability to control one's emotions, awareness of one's wishes, the ability to persevere in case of difficulties, the ability to control one's behaviour, the ability to express his/her attitude towards what is happening, the independent organisation of activities and actions, the ability to ask and answer questions about oneself and one's skills, the ability to organise work, the ability to enjoy studying, the ability to listen and perceive what is heard (i. e., answers questions, explains, tells), and the ability to express one's attitude towards creative work. 
In the self-regulated learning process, the teacher provides support, encouragement, motivation and praise, while the child learns to develop his/her self-regulation skills, which includes learning to think, do, find out, and look for answers within oneself.

In order to better develop the self-regulatory process for 5 to 6 -year-old children, the self-regulated learning process should be easy to understand, with an emphasis on updating, understanding and reflecting on the learning content, as well as clearly articulating the results to be achieved and providing feedback.

Although the normative documents (Cabinet regulations, 2018 (716)) ations regarding the state pre-school education guidelines and samples of pre-school education programs, 2018) and pre-school curriculum emphasise self-regulated learning, as the results of this research show, it is necessary to strengthen self-regulated learning principles by implementing self-directed learning phases (i. e., planning, monitoring and assessment) together with children, and to promote children's thinking, emotional processes, and behavioural self-regulation.

\section{References}

Becker, D. R., McClelland, M., Loprinzi, P., \& Trost, S. G. (2014). Physical activity, selfregulation, and early academic achievement in preschool children. Early Education and Development, 25, 56-70. https://doi.org/10.1080/10409289.2013.780505

Blair, C. (2002). School readiness: Integrating cognition and emotion in a neurobiological conceptualization of children's functioning at school entry. American Psychologist, 57, 111-127.

Blair, C. (2003). Self-regulation and school readiness. Champaign, IL: ERIC Clearinghouse on Elementary and Early Childhood Education. (ERIC Document Reproduction Service No. ED477640)

Boekaerts, M., \& Corno L. (2005). Self-regulation in the classroom: A perspective on assessment and intervention. Applied Psychology 54(2), 199-231. https://psycnet.apa. org/doi/10.1111/j.1464-0597.2005.00205.x

Braaka, D., Størksen, I., Idsoe, T., \& McClelland, M. (2019). Bidirectionality in selfregulation and academic skills in play-based early childhood education. Journal of Applied Developmental Psychology, 65, 101064.

Calkins, S. (2004). Early attachment processes and the development of emotional selfregulation. In R. F. Baumeister \& K. D. Vohs (Eds.), Handbook of self-regulation: Research, theory, and applications (pp. 324-340). The Guilford Press.

Dörr, L., \& Perels, F. (2019). Improving metacognitive abilities as an important prerequisite for self-regulated learning in preschool children. International Electronic Journal of Elementary Education, 11(5), 449-459 https://doi.org/10.26822/iejee.2019553341

Jacoba, L., Dörrenbächerb, S., \& Perels, F. (2019). Pilot study of the online assessment of self-regulated learning in preschool children: Development of a direct, quantitative measurement tool. International Electronic Journal of Elementary Education, 12(2), 115-126A. 
Knowles, M. S. (1975). Self-directed learning. Association Press.

Liman, B., \& Tepeli, K. (2019). Study on the effects of self-regulation skills education program on self-regulation skills of six-year-old children. Educational Research and Reviews, 14(18), 647-654. https://doi.org/10.5897/ERR2019.385310.5897/ERR2019.3853

Lonigan, C. J., Allan, D. M., \& Phillips, B. M. (2017). Examining the predictive relations between two aspects of self-regulation and growth in preschool children's early literacy skills. Developmental Psychology, 53(1), 63-76.

McClelland, M. M., \& Cameron, C. E. (2012). Self-regulation in early childhood: Improving conceptual clarity and developing ecologically valid measures. Child Development Perspectives, 6, 136-142. https://doi.org/10.1111/j.1750-8606.2011.00191.x

Murray, D. W., Rosanbalm, K., Christopoulos, C., \& Hamoudi, A. (2015). Self-regulation and toxic stress: Foundations for understanding self-regulation from an applied perspective (OPRE Report \#2015). Office of Planning, Research and Evaluation. https://www. researchconnections.org/childcare/resources/30359/pdf

Regulations Regarding the State Guidelines for Pre-school Education and the Model Pre-school Education Programmes 2018(716). https://likumi.lv/ta/en/en/id/303371

Panadero, E., \& Järvelä, S. (2015). Socially shared regulation of learning: A review. Eur. Psychol. 20, 190-203. https://doi.org/10.1027/1016-9040/a000226

Pilling-Cormick, J., \& Garrison, D. R. (2007). Self-directed and self-regulated learning: Conceptual links. Canadian Journal of University Continuing Education, 33(2), 13-33. https://doi.org/10.21225/D5S01M

Pintrich, P. R. (2000). The role of goal orientation in self-regulated learning. In M. Boekaerts, P. R. Pintrich \& M. Zeidner (Eds.), Handbook of self-regulation (pp. 451502). Academic Press.

Posner, M. I., \& Rothbart, M. K. (2000). Developing mechanisms of self-regulation. Development and Psychopathology, 12(3), 427-441. https://psycnet.apa.org/doi/10.1017/ S0954579400003096

Rosanbalm, K. D., \& Murray, D. W. (2017). Promoting self-regulation in early childhood: A practice brief (OPRE Brief \#2017-79). Office of Planning, Research, and Evaluation. https://fpg.unc.edu/sites/fpg.unc.edu/files/resources/reports-and-policy-briefs/ PromotingSelf-RegulationIntheFirstFiveYears.pdf

Rothbart, M. K., \& Bates, J. E. (2006). Temperament. In N. Eisenberg, W. Damon, \& R. M. Lerner (Eds.), Handbook of child psychology: Social, emotional, and personality development (pp. 99-166). John Wiley \& Sons, Inc.

Savina, E. (2021). Self-regulation in preschool and early elementary classrooms: Why it is important and how to promote it. Early Childhood Educ J, 49, 493-501. https://doi.org/ 10.1007/s10643-020-01094-w

Zimmerman, B. J. (2005). Attaining self-regulation: A social cognitive perspective. In M. Boekaer, P. R. Pintrich, \& M. Zeidner (Eds.) Handbook of self-regulation (pp. 13-39). Elsevier Academic Press.

Zimmerman, B. J., \& Schunk, D. H. (2011). Self-regulated learning: An introduction and an overview. In Handbook of self-regulated learning and performance (pp. 1-12). Routledge. 